\title{
Verification of Inverse Image Source Method Applied for Acoustic Field Creation in Open Area
}

\author{
A. Gołaś, K. Suder-Dębska*, W. Ciesielka and R. Filipek \\ Department of Power Engineering and Environmental Protection \\ AGH - University of Science and Technology, al. A. Mickiewicza 30, 30-059 Kraków, Poland
}

\begin{abstract}
The paper presents an original method for sound reinforcement in open areas. The method enabled both a regular sound reinforcement and the required spatial impressions of sound to be achieved in the area used for the study. The inverse image source method was used for the disposition of sound sources in order to find the inverse problem solution for determining the configuration of additional sound sources. Simulations demonstrated the improvement of sound impressions in the area in question and the simulations results were verified experimentally. The intended result of the proposed method was the increase of the lateral energy fraction and lateral energy fraction coefficient parameter values by 6 and 8 points, respectively, for the simulation by 5 and 7 points for the experiment. It should be stated that, in both the simulation and the experiment, eligible values for the acoustic parameters were obtained after using the sound system with additional sound sources, the speech intelligibility value parameters remain at an excellent level. In conclusion, it may be claimed that the proposed sound reinforcement system makes the creation of the intended spatial sound impressions in an open area possible.
\end{abstract}

PACS: 43.55.-n, 43.55.+p, 43.55.Ka, 43.55.Jz, 43.58.Ta

\section{Introduction}

Direct sound predominates in open areas. Propagation of acoustic waves is realized in straight lines, without barriers and diffraction which means that the sound is not reflected, absorbed, diffracted, refracted, scattered and subjected to the resonance effect [1]. Reflected or scattered sound occurs in much more limited extent than in enclosures, which causes that its spaciousness is very limited (in case of classic configurations of electro-acoustic installations). For this reason the most important and preferred acoustic parameter determined for sound system in an open area was the sound pressure level (SPL), the other parameters are determined much more seldom $[2,3]$.

During a sound reinforcement in open areas by means of so-called wall of sound it is possible to create the acoustic field in two ways: in case of small areas — by means of loudspeaker sets with a large power, located centrally (on stage) and in case of large areas - by means of multi-zone sound reinforcement [4-6]. An alternative method is application of line arrays systems, that comparing with the wall of sound they enable obtaining of more uniform sound field distribution in the area of entire amplified surface [7-14]. In both cases the purpose is to ensure an appropriate SPL in sound amplification area.

The analysis of acoustic field was performed already in ancient time (graphical method), in 19th century W.C. Sabine has created a statistical theory of acoustic field and in the 20th century development of wave methods and geometrical methods took place. In the last dozens

* corresponding author; e-mail: suder@agh.edu.pl of years primary geometrical methods, ray method and image source methods, have evolved and their modifications make currently possible omitting of some limitations characteristic for geometrical methods in primary form [15-18]. Most common application of geometrical methods is the analysis of acoustic field in real or virtual objects being in the project stage, which enables possible changes in the project and improvement of acoustic properties of objects $[19,20]$. Except of the analysis of influence of the shape and features of the object on its acoustic properties, simulation programs based upon geometrical methods enable also analysis of acoustic field distribution depending on location and character of the sound source or sound sources [21-23]. Results of simulation performed on the basis of geometrical methods are reflecting to a high degree the state from real objects $[24,25]$. It is necessary to point out that it is still the area of analysis of acoustic field, i.e. at known features of the object and known distribution of sound sources the sound field distribution is determined.

In this elaboration the image source method in an innovative way has been used, i.e. by means of this method the distribution of sound sources creating the acoustic field in an open area has been determined, characterised by such properties that the listener has an impression that he is in a closed object with good acoustic properties. In open areas, as mentioned above, spatial impressions are very limited, so it was very important to create such sound reinforcement system, that could improve impression of spatial sound. To improve this impression, a unique technique has been applied - introducing into area of additional sound sources simulating reflections of sound from walls, the arrangement and parameters of which have been determined by means of inverse image 
source method. The image source method has been used for solving of an inverse problem, i.e. initially the desirable values of acoustic parameter [26] have been assumed and then on the basic of image source method such distribution of sound sources has been determined to obtain values of acoustic parameters close to assumed ones. The values are selected in such way that in the result of amplified open area it could be possible to obtain an acoustic field with properties close to the properties of acoustic field obtained in a good concert hall [27-29]. Algorithm of proceeding is as follows [30]:

1. assumption of desirable values of acoustic field parameters for an interesting object;

2. restricting of an open area with walls of a virtual room;

3. determining of acoustic field distribution in the virtual room;

4. determining of coordinates of additional sound sources, creating acoustic field fulfilling the assumed quality criteria.

Because the tested area was an open area, the attention was primarily drawn to parameters speaking about impressions of spatial sound - parameters from group Lateral Sound. As a result of performed experiments we can say that regarding the spatial impression of sound, the quality of received sound in an open area has been considerably improved in relation to quality of the sound obtained with classical amplification, i.e. if the loudspeakers were arranged on the sides of stage.

\section{A studied object}

For the purposes of the study, an open area, measuring $24 \times 32 \mathrm{~m}^{2}$, was assumed. A virtual room, measuring $24 \times 32 \times 4 \mathrm{~m}^{3}$, was overlapped on it. The walls were numbered as follows: 1 - the wall behind the stage, 2 the wall behind the audience, 3 and 4 - the side walls, 5 - the floor, and 6 - the ceiling. Total absorption was assumed for the wall behind the stage and the ceiling (absorption coefficient equal to 1 ). The absorption coefficient for walls 2,3 and 4 is equal to 0 (total reflection of sound). Image sources were calculated for neither the stage wall (wall 1) nor the floor and ceiling (walls 5 and 6 ). First and second order image sources were considered. The area contains no elements apart from the audience and the grass. The origin of the coordinate system was placed in the geometric center of the area. A real sound source was placed at coordinates 14,0,0.567 different source-receiver configurations were considered. The receivers were located at a distance of $1 \mathrm{~m}$. In the simulations for the real sound source SPL equal to $100 \mathrm{~dB}$ was assumed. The additional sound sources parameters are shown in Table I and in Fig. 1.

A numerical model of the open area, with the virtual room overlapped, but with absorption coefficient for the

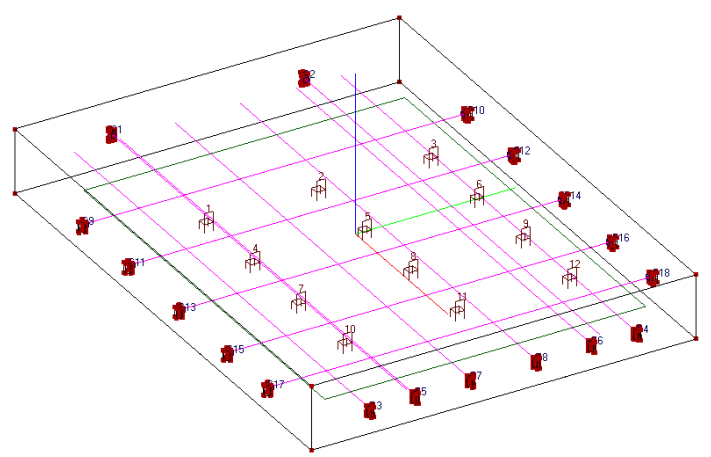

Fig. 1. Location of sound sources and measurement points $(1-12)$.

Parameters of sound sources.

TABLE I

\begin{tabular}{c|c|c|c|c|c}
\hline \hline \multirow{2}{*}{$\begin{array}{c}\text { Source } \\
\text { number }\end{array}$} & \multicolumn{2}{|c|}{ Sound source coordinates } & Power level & $\begin{array}{c}\text { Delay } \\
{[\mathrm{dB}]}\end{array}$ \\
\hline 1 & $x$ & $y$ & $z$ & 100.0 & 0.000 \\
2 & -16.00 & -6.00 & 0.00 & 100.0 & 0.000 \\
3 & 16.00 & -8.30 & -0.50 & 73.3 & 0.091 \\
4 & 16.00 & 8.30 & -0.50 & 73.3 & 0.091 \\
5 & 16.00 & -5.50 & -0.45 & 66.0 & 0.120 \\
6 & 16.00 & 5.50 & -0.45 & 66.0 & 0.120 \\
7 & 16.00 & -2.05 & -0.45 & 70.0 & 0.107 \\
8 & 16.00 & 2.05 & -0.45 & 70.0 & 0.107 \\
9 & -8.70 & -12.00 & -0.30 & 88.3 & 0.040 \\
10 & -8.70 & 12.00 & -0.30 & 88.3 & 0.040 \\
11 & -3.70 & -12.00 & -0.35 & 87.0 & 0.050 \\
12 & -3.70 & 12.00 & -0.35 & 87.0 & 0.050 \\
13 & 1.75 & -12.00 & -0.40 & 83.0 & 0.063 \\
14 & 1.75 & 12.00 & -0.40 & 83.0 & 0.063 \\
15 & 6.95 & -12.00 & -0.45 & 80.0 & 0.070 \\
16 & 6.95 & 12.00 & -0.45 & 80.0 & 0.070 \\
17 & 11.30 & -12.00 & -0.45 & 70.3 & 0.112 \\
18 & 11.30 & 12.00 & -0.45 & 70.3 & 0.112 \\
& & & & &
\end{tabular}

walls and ceiling equal to 1, was created using the enhanced acoustic simulator for engineers (EASE 4.2 [31]) software. The simulation was run in the following variants:

1. for two speakers with a $100 \mathrm{~dB}$ power level placed on the stage;

2. for two speakers placed on the stage, with additional speakers creating acoustic spatial impressions, where the power level of the stage sources was $100 \mathrm{~dB}$ and those of the additional sources were correspondingly lower (Table I).

The goal of the numerical simulation was the determination of the values for the following acoustic parameters [1]: 


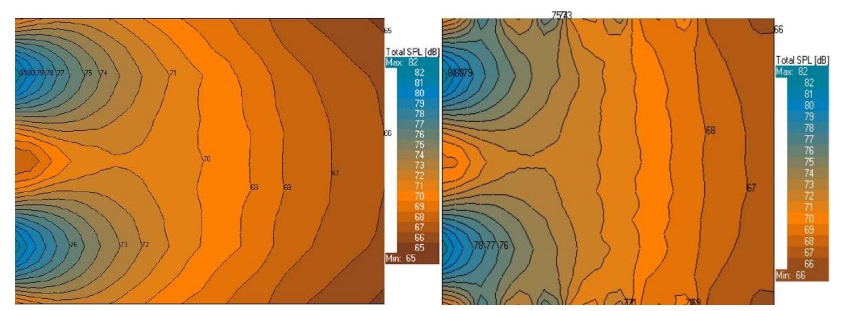

Fig. 2. Distribution of SPL for variant 1 (left) and for variant 2 (right).

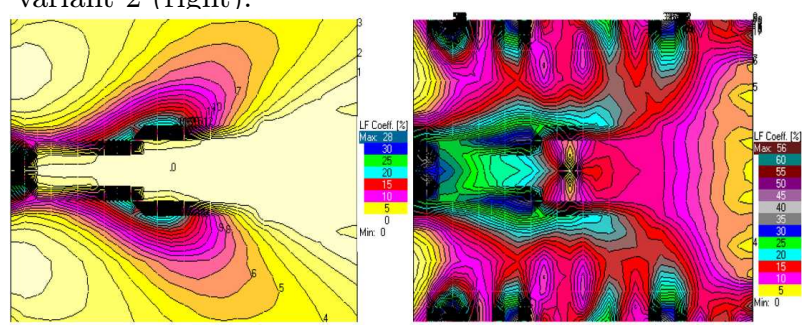

Fig. 3. Distribution of LFC for variant 1 (left) and for variant 2 (right).

- sound pressure level $S P L[\mathrm{~dB}]$ defined as a logarithmic measure of the effective sound pressure of a sound $p$ relative to a reference value $p_{0}$ :

$$
\mathrm{SPL}=20 \log \frac{p}{p_{0}} \text {. }
$$

- definition $D$ - early-to-late energy ratio, characterising the speech intelligibility

$$
D=\int_{0}^{50 \mathrm{~ms}}|p(t)|^{2} \mathrm{~d} t / \int_{0}^{\infty}|p(t)|^{2} \mathrm{~d} t
$$

where $p(t)$ — sound pressure impulse response;
- clarity $C_{80}[\mathrm{~dB}]$ - early-to-late energy ratio for music, characterising the subjective transparency

$$
C_{80}=10 \log \int_{0}^{80 \mathrm{~ms}}|p(t)|^{2} \mathrm{~d} t / \int_{80 \mathrm{~ms}}^{\infty}|p(t)|^{2} \mathrm{~d} t ;
$$

- clarity $C_{50}[\mathrm{~dB}]$ - early-to-late energy ratio for speech, characterizing the speech intelligibility

$$
C_{50}=10 \log \int_{0}^{50 \mathrm{~ms}}|p(t)|^{2} \mathrm{~d} t / \int_{50 \mathrm{~ms}}^{\infty}|p(t)|^{2} \mathrm{~d} t
$$

- lateral energy fraction $L F$ - early lateral sound ratio, characterizing the subjective spatial impression "apparent source width"

$$
\mathrm{LF}=\int_{5}^{80 \mathrm{~ms}}\left|p_{\mathrm{L}}(t)\right|^{2} \mathrm{~d} t / \int_{0 \mathrm{~ms}}^{80 \mathrm{~ms}}|p(t)|^{2} \mathrm{~d} t,
$$

where $p_{\mathrm{L}}(t)$ - lateral sound pressure impulse response (figure-of-eight directionality) with its directional null pointed towards the source;

- lateral energy fraction coefficient $L F C$

$$
\mathrm{LFC}=\int_{5}^{80 \mathrm{~ms}}\left|p_{\mathrm{L}}(t) * p(t)\right| \mathrm{d} t / \int_{0 \mathrm{~ms}}^{80 \mathrm{~ms}}|p(t)|^{2} \mathrm{~d} t
$$

- speech transmission index STI characterizing the speech intelligibility.

The SPL and LFC parameter distributions resulting from the simulations are shown in Figs. 2 and 3 . In Table II, the results of the numerical simulations in several points (Fig. 1) for the electro-acoustic installation with additional loudspeakers, are given.

Results of the numerical simulation for measurement points.

TABLE II

\begin{tabular}{c|c|c|c|c|c|c|c}
\hline \hline Point & SPL [dB] & Definition [\%] & $C_{50}[\mathrm{~dB}]$ & $C_{80}[\mathrm{~dB}]$ & LF [\%] & LFC [\%] & STI \\
\hline 1 & 74.31 & 96.69 & 14.66 & 24.04 & 7.02 & 9.50 & 0.893 \\
2 & 72.10 & 90.02 & 9.55 & 25.59 & 18.38 & 19.89 & 0.838 \\
3 & 74.28 & 96.55 & 14.48 & 23.92 & 6.97 & 9.48 & 0.891 \\
4 & 71.75 & 94.60 & 12.44 & 23.60 & 7.36 & 11.35 & 0.886 \\
5 & 71.61 & 95.48 & 13.26 & 25.92 & 8.24 & 12.27 & 0.860 \\
6 & 71.74 & 94.68 & 12.51 & 23.59 & 6.92 & 10.70 & 0.888 \\
7 & 69.72 & 94.79 & 12.60 & 25.94 & 7.80 & 13.64 & 0.896 \\
8 & 70.36 & 99.08 & 20.34 & 24.16 & 9.03 & 10.96 & 0.893 \\
9 & 69.90 & 94.69 & 12.51 & 26.22 & 8.28 & 14.31 & 0.897 \\
10 & 68.20 & 96.81 & 14.82 & 29.71 & 6.78 & 12.13 & 0.921 \\
11 & 68.87 & 98.89 & 19.49 & 39.30 & 6.79 & 7.98 & 0.926 \\
12 & 68.64 & 97.20 & 15.40 & 30.00 & 6.30 & 11.54 & 0.928
\end{tabular}

\section{The experiments}

The experiment was carried out in line with the standard [32]. The objective of the research was to establish the LF and LFC parameters which describe the spatial impressions of the sound.

Acoustic field creation in the open area was obtained by a multi-channel sound system (Fig. 4) built from elements that create three electroacoustic lines, as follows:

1. the basic line: a PC, a Waveterminal U2A sound card, two channels of an MPA6-150, multi-channel power amplifier and two Zeck Club 212.1 loudspeakers; 
2. the additional line: a PC, a Waveterminal U2A sound card, an ADSP-BF537 processor with an Analog Devices extension card, sixteen channels of three MPA6-150 multi-channel power amplifiers and sixteen Visaton BG17 loudspeakers;

3. the measurements line: an ECM-170 measurement microphone with switched directivity pattern (omnidirectional and figure-of-eight), a PC, a Waveterminal U2A sound card and an Svan945A meter.

The heart of the assembled control system consists of a digital filters system and digital delay lines, implemented in ADSP BF-537, and an Analog Device Company multi-channel card, equipped with an extension module. The software part of the system was developed with VisualDSP ++ environment.

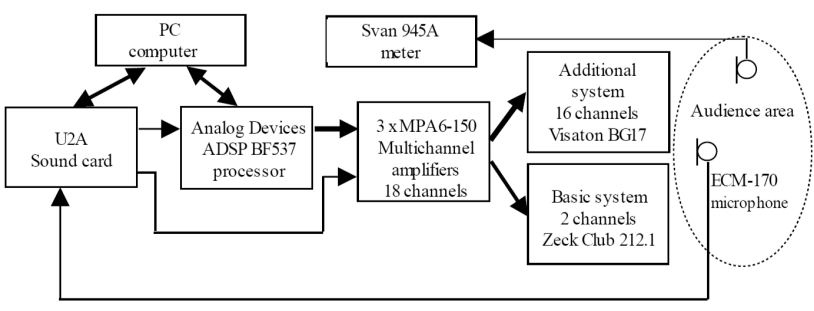

Fig. 4. Multi-channel sound system in the open area.

Sixteen identical sound sources, based on the broadband Visaton BG-17 loudspeaker, as shown in Fig. 5a, were designed for the abovementioned sound system [33]. Selected loudspeaker technical data are presented in Table III and in Fig. 5b. The design and shape of the speaker enclosure created for the study resulted from a compromise between three factors; ensuring the best performance characteristics, considerations of price and the ability to compile the same sources in multi-channel electro-acoustic systems. Directivity patterns and other parameters for the designed loudspeaker system can be found at [34].
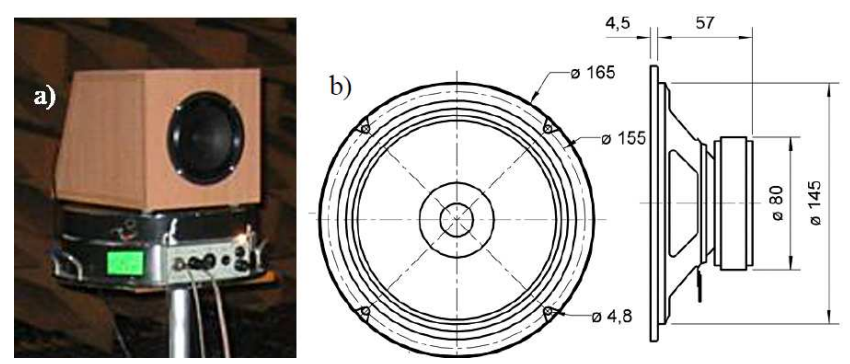

Fig. 5. (a) Visaton BG-17 loudspeaker in enclosure, (b) BG-17 geometrical parameters.

For measurement, the maximum length sequence (MLS) signal was used, emitted first by the basic line with two channels, and then by the sixteen linked channels of the additional line. The configuration of the measurement points is presented in Fig. 1. Impulse responses
Selected loudspeaker technical data.

TABLE III

\begin{tabular}{l|l|l}
\hline \hline rated power & 40 & $\mathrm{~W}$ \\
nominal impedance & 8 & $\Omega$ \\
frequency response & $80-20000$ & $\mathrm{~Hz}(-10 \mathrm{~dB})$ \\
mean sound pressure level & 93 & $\mathrm{~dB}(1 \mathrm{~W} / 1 \mathrm{~m})$ \\
resonance frequency [fs] & 110 & $\mathrm{~Hz}$ \\
total Q factor (Qts) & 0.64 & \\
equivalent volume (Vas) & 9.7 & $\mathrm{l}$
\end{tabular}

were calculated for each of two variants; the acoustic parameters were then calculated on the basis of the results. The microphones were situated at a height of $1.4 \mathrm{~m}$, the measurement points were $5 \mathrm{~m}$ away from side walls and the rear wall, and the distance between several points was also $5 \mathrm{~m}$. The measurement results for the sound system with additional sound sources are presented in Table IV.

\section{Analysis of results and conclusions}

The comparison of acoustic parameter values, obtained for a sound system with additional loudspeakers by means of simulation and measurement is presented in Table V. The discrepancy between the parameter values obtained for the traditional sound reinforcement system and the sound reinforcement system with additional loudspeakers are presented in Figs. 6-8.

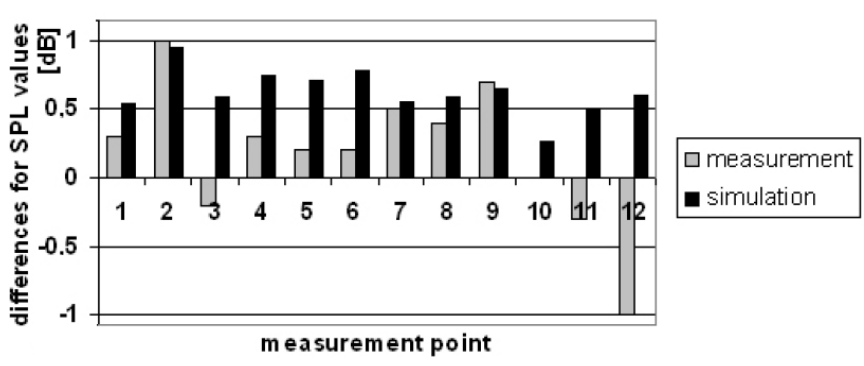

Fig. 6. Differences between SPL values at measurement points, without and with additional sound system.

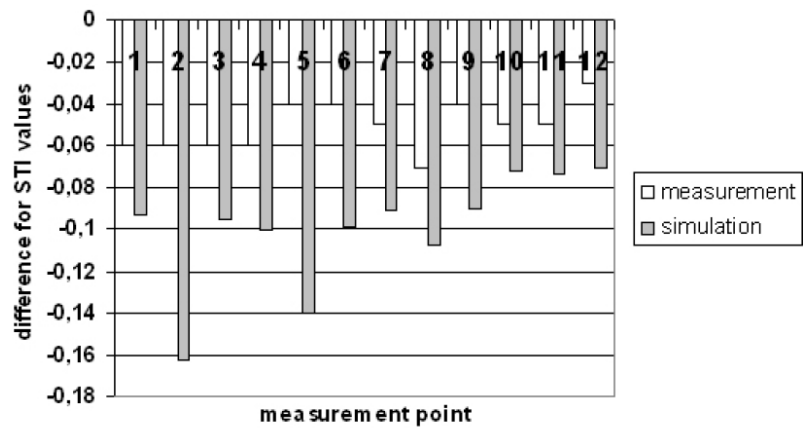

Fig. 7. Differences between LF values at measurement points, without and with additional sound system. 


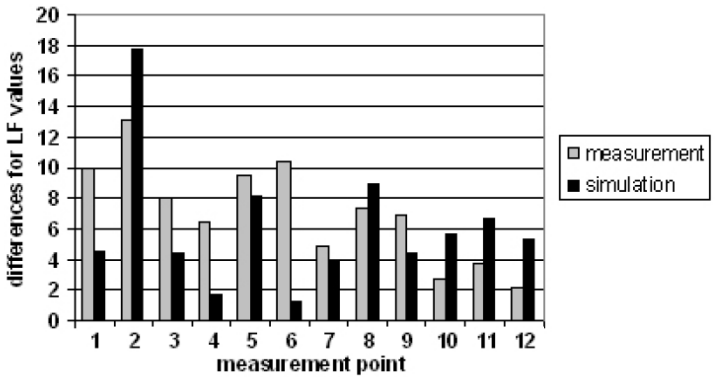

Fig. 8. Differences between STI values at measurement points, without and with additional sound system.
On the basis of this analysis, it may be posited that the insertion of additional sound sources resulted in improved spatial sensations. The objective of study was the increase of the LF and LFC parameter values by 6 and 8 points, respectively, for the simulation and 5 and 7 points for the experiment. For both the simulations and the measurements taken after the application of additional sound sources in the audience area, eligible values of quality criteria were obtained.

Measurement result for sound system with additional sound sources.

TABLE IV

\begin{tabular}{c|c|c|c|c|c|c|c}
\hline \hline Point & SPL [dB] & Definition [\%] & $C_{50}[\mathrm{~dB}]$ & $C_{80}[\mathrm{~dB}]$ & LF [\%] & LFC [\%] & STI \\
\hline 1 & 77.20 & 98.60 & 18.47 & 22.81 & 13.20 & 8.90 & 0.87 \\
2 & 72.70 & 93.20 & 11.37 & 18.61 & 16.50 & 11.40 & 0.84 \\
3 & 75.80 & 98.63 & 18.56 & 24.20 & 10.10 & 7.00 & 0.86 \\
4 & 73.70 & 97.63 & 16.14 & 20.52 & 11.60 & 10.10 & 0.88 \\
5 & 71.70 & 97.07 & 15.20 & 20.13 & 11.80 & 7.30 & 0.88 \\
6 & 72.60 & 97.32 & 15.60 & 19.38 & 15.40 & 12.90 & 0.86 \\
7 & 71.50 & 97.83 & 16.54 & 20.37 & 9.60 & 9.50 & 0.87 \\
8 & 70.20 & 97.71 & 18.74 & 22.33 & 10.20 & 8.80 & 0.84 \\
9 & 70.70 & 96.14 & 13.96 & 18.17 & 11.60 & 12.10 & 0.85 \\
10 & 69.40 & 95.61 & 13.38 & 19.94 & 9.70 & 10.60 & 0.84 \\
11 & 67.90 & 95.23 & 13.00 & 18.03 & 6.50 & 6.40 & 0.84 \\
12 & 68.30 & 95.13 & 12.91 & 18.62 & 10.30 & 17.20 & 0.86
\end{tabular}

TABLE V

Discrepancies in parameter values between simulation and measurement.

\begin{tabular}{c|c|c|c|c|c|c|c}
\hline \hline \multirow{2}{*}{ Point } & \multicolumn{2}{|c}{ Discrepancies in parameter values between simulation and measurement } \\
\cline { 2 - 7 } & for & for & for & for & for & for & for \\
& SPL & Definition & $C_{50}$ & $C_{80}$ & LF & LFC & STI \\
\hline 1 & -2.89 & -1.91 & -3.81 & 1.23 & -6.18 & 0.60 & 0.02 \\
2 & -0.60 & -3.18 & -1.82 & 6.98 & 1.88 & 8.49 & 0.00 \\
3 & -1.52 & -2.08 & -4.08 & -0.28 & -3.13 & 2.48 & 0.03 \\
4 & -1.95 & -3.03 & -3.70 & 3.08 & -4.24 & 1.25 & 0.01 \\
5 & -0.09 & -1.59 & -1.94 & 5.79 & -3.56 & 4.97 & -0.02 \\
6 & -0.86 & -2.64 & -3.09 & 4.21 & -8.48 & -2.20 & 0.03 \\
7 & -1.78 & -3.04 & -3.94 & 5.57 & -1.80 & 4.14 & 0.03 \\
8 & 0.16 & 1.37 & 1.60 & 1.83 & -1.17 & 2.16 & 0.05 \\
9 & -0.80 & -1.45 & -1.45 & 8.05 & -3.32 & 2.21 & 0.05 \\
10 & -1.20 & 1.20 & 1.44 & 9.77 & -2.92 & 1.53 & 0.08 \\
11 & 0.97 & 3.66 & 6.49 & 21.27 & 0.29 & 1.58 & 0.09 \\
12 & 0.34 & 2.07 & 2.49 & 11.38 & -4.00 & -5.66 & 0.07
\end{tabular}

It was predictable that, after the application of additional sound sources in the studied area, there may well be a decrease in speech intelligibility parameter values. However, in both the simulation and the experiment, the speech intelligibility parameter values maintained an excellent level after the application of the sound system with additional sound sources. This was also verified by the definition parameter, which achieved $90 \%$ for the sim- 
ulations and measurements alike. It could be observed that, for the measurements, higher values were obtained for the left side of the audience area (points: 1, 4, 7, 10) than for the right one. This may have been caused by the fact that the measurement area was not an ideal open area, given that, at $c a .1 \mathrm{~m}$ high, the rear and sides at walls 2 and 3 were rather low and both the concrete wall and the area itself were surrounded by shrubs, which might have generated additional reflection and amplified the sound. This effect was not observed in the simulation owing to the simplification and idealization of the assumed model.

The discrepancy in the LF parameter values of the simulations and measurements could be the result of the less than ideal conditions of the open area in the experiment giving rise to higher LF parameter values. These differences might also be the effect of the loudspeaker properties; eighteen identical loudspeakers were used in the simulation, while the set of base and additional loudspeakers were different for the measurement. The third factor which may have caused the differences is the limitations of the geometrical methods implemented in the simulations software.

In conclusion, it can be claimed that the aim of the study was achieved, inasmuch as the distribution of the sound pressure level was more equable and the spatial impressions of sound were improved for the sound system with additional loudspeakers, while speech intelligibility was only decreased to a slight degree.

\section{References}

[1] F.P. Mechel, Formulas of Acoustics, Springer-Verlag, Berlin 2008.

[2] P. Thomas, T. Van Renterghem, D. Botteldooren, Appl. Acoust. 72, 201 (2011).

[3] J. Kang, J. Acoust. Soc. Am. 117, 3695 (2005).

[4] E. Hojan, The principles of creating sound systems in rooms and open space, Wydawnictwo Naukowe UAM, Poznań 2003 (in Polish).

[5] G. Ballou, Handbook for Sound Engineers, Focal Press, USA 2008.

[6] M. Ishizawa, Y. Mafune, H. Endo, Y. Riko, Acta Acust. 84, 311 (1998).

[7] H.F. Olson, Elements of Acoustical Engineering, D. Van Nostrand Co., New York 1940.

[8] M. Bailey, in: Proc. AES 18th UK Conf., 2003.
[9] C. Heil, M. Urban, in: Proc. 92nd AES Convention, 1992.

[10] M.S. Ureda, in: Proc. 110th AES Convention, 2001.

[11] M.S. Ureda, in: Proc. 111th AES Convention, 2001.

[12] M.S. Ureda, in: Proc. 113th AES Convention, 2002.

[13] M.S. Ureda, J. Audio Eng. Soc. 52, 467 (2004).

[14] B. Webb, J. Baird, in: Proc. AES 18th UK Conf., 2003.

[15] T. Funkhouser, N. Tsingos, I. Carlbom, G. Elko, M. Sondhi, J.E. West, G. Pingali, P. Min, A. Ngan, J. Acoust. Soc. Am. 115, 739 (2004).

[16] N. Campo, P. Rissone, M. Toderi, Appl. Acoust. 61, 199 (2000).

[17] Z. Xiangyang, Ch. Ke-an, S. Jincai, Appl. Acoust. 63, 481 (2002).

[18] A. Gołaś, Computer methods for acoutics of interiors and environment, Wydawnictwa AGH, Kraków 1995 (in Polish).

[19] M. Galino, T. Zamarreno, S. Giron, J. Acoust. Soc. Am. 126, 1207 (2009).

[20] F. Martellotta, J. Acoust. Soc. Am. 126, 1175 (2009).

[21] L.M. Wang, M.C. Vigeant, Appl. Acoust. 69, 1281 (2008).

[22] Z. Xiangyang, Ch. Ke-an, S. Jincai, Acta Acust. united with Acustica 88, 88 (2002).

[23] A. Gołaś, K. Suder-Dębska, R. Filipek, Acta Phys. Pol. A 118, 62 (2010).

[24] I. Bork, Acta Acust. united with Acustica 86, 943 (2000).

[25] A. Gołaś, K. Suder-Dębska, Arch. Acoust. 34, 273 (2009).

[26] Springer Handbook of Acoustics, Ed. T. Rossing, Springer Science + Business Media, LLC, New York 2007.

[27] Y. Ando, Concert Hall Acoustics, Springer-Verlag, Berlin 1985.

[28] A.H. Marshall, M. Barron, Appl. Acoust. 62, 91 (2001).

[29] M. Barron, Appl. Acoust. 62, 185 (2001).

[30] A. Gołaś, K. Suder-Dębska, in: Proc. 17th Int. Congress on Sound and Vibration, Cairo 2010.

[31] EASE 4.2 Users Manual, Acoustic Design Ahnert, Berlin 2008.

[32] ISO 3382-2:2008, Measurement of Room Acoustic Parameters.

[33] W. Ciesielka, Arch. Acoust. 34, 559 (2009).

[34] W. Ciesielka, Arch. Acoust. 32, Suppl. 1 (2007). 